\title{
Smoking and risk of cholangiocarcinoma: a systematic review and meta-analysis
}

\author{
Yuenan Huang ${ }^{1, *}$, Liuping You ${ }^{1, *}$, Weimin Xie ${ }^{2, *}$, Li Ning ${ }^{2, *}$ and Jinghe Lang ${ }^{2}$ \\ ${ }^{1}$ Department of General Surgery, The Second Affiliated Hospital, Harbin Medical University, Harbin, China \\ ${ }^{2}$ Department of Obstetrics and Gynecology, Peking Union Medical College Hospital, Chinese Academy of Medical Sciences and \\ Peking Union Medical College, Beijing, China \\ *These authors contributed equally to this work
}

Correspondence to: Yuenan Huang, email: dr-huangyuenan@163.com

Keywords: smoking, cholangiocarcinoma, risk, meta-analysis

Received: May 01, 2017 Accepted: July 30, $2017 \quad$ Published: August 10, 2017

Copyright: Huang et al. This is an open-access article distributed under the terms of the Creative Commons Attribution License 3.0 (CC BY 3.0), which permits unrestricted use, distribution, and reproduction in any medium, provided the original author and source are credited.

\section{ABSTRACT}

\begin{abstract}
Previous studies evaluating the association between smoking and risk of cholangiocarcinoma (CCA) have yielded controversial results. We conducted a metaanalysis to evaluate the association based on available evidence. We searched the databases of Embase, PubMed and Cochrane Central Register of Controlled Trials from inception to April 11, 2017. Studies that investigated the association between smoking and risk of CCA were included. Pooled odds ratio (OR) estimates and $95 \%$ confidence intervals (CIs) were calculated using either a random-effects or a fixedeffects model. A total of 22 studies involving 324,333 participants were identified. The summary OR of CCA was 1.31 ( $95 \%$ CI, 1.15 to 1.51$)$ for smokers versus nonsmokers. The increased risk was independent of diabetes mellitus, bilious tract stone disease, and liver cirrhosis. Smokers also had increased risk of intrahepatic CCA (12 studies; OR, 1.31; 95\% CI, 1.06 to 1.63 ) and extrahepatic CCA (12 studies; OR, 1.32; 95\% CI, 1.10 to 1.59) compared with nonsmokers. The results of our meta-analysis support the hypothesis that there is a moderate association between cigarette smoking and risk of CCA.
\end{abstract}

\section{INTRODUCTION}

Cholangiocarcinoma (CCA), the second most common primary hepatobiliary carcinoma, is an enigmatic and aggressive malignancy originating from the epithelium of the biliary tract system [1]. It can be classified into two anatomic subtypes: intrahepatic and extrahepatic [2]. Extrahepatic CCA can be further divided anatomically into perihilar and distal CCA [3]. CCA is a devastating carcinoma with a dismal 5-year overall survival rate of less than $10 \%$ [4]. Despite the significant geographic variation in its incidence, worldwide epidemiological data have shown an increasing trend in the past few years [5]. Several risk factors have been proposed to be involved in the etiology of CCA. Certain diseases, including primary sclerosing cholangitis, cholelithiasis, hepatitis $\mathrm{B}$ and $\mathrm{C}$ infection, and diabetes mellitus, have been linked to increased risk of CCA
[2, 6-9]. Parasite infection with Opisthorchis viverrini and Clonorchis sinensis, and exposure to the toxic agent thorotrast have also been associated with the development of CCA [10-11]. However, these risk factors are quite variable in different areas of the world, and some remain controversial.

Several compounds of cigarette smoke have been shown to have a carcinogenic effect in preclinical studies. For instance, N-Nitrosodimethylamine is carcinogenic in many species including rats, mice and monkeys, and is known to cause liver cancer [12]. Interestingly, it has also been shown to cause CCA in mice [13]. Cigarette smoking has been shown to have a tumorigenic effect in a wide variety of malignancies, including the oral cavity, pharynx, larynx, lung, esophagus, stomach, pancreas, liver, cervix, and kidney [14]. As such, smoking is strongly associated with malignancies of the respiratory tract system, but even the gastrointestinal and urogenital systems show a 
substantial increase in cancer risk with smoking. However, the evidence for CCA is contradictory.

This study aimed to evaluate the association between smoking and risk of CCA through a systematic review of available evidence.

\section{RESULTS}

\section{Study selection}

A total of 479 records were identified through database searching; no additional records were found from ongoing trials and conference proceedings. After removing duplicates and strict screening, 35 potentially relevant records were retrieved for detailed review. A total of 13 of these 35 records were subsequently excluded for the following reasons: six were duplicate reports from the same population [15-20], and seven did not have data specific for CCA [21-27]. No records were identified from reference lists. Thus, a total of 22 studies were included in this meta-analysis [28-49]. The flow diagram summarizing the selection process is given in Figure 1.

\section{Study characteristics}

All included studies were case controls [28-49], that included a total of 324,333 participants and published between 1993 and 2016. The number of patients with CCA ranged from 6 to 2,395. One of the 22 studies was published only in abstract form [47]. Eight studies were carried out in North America [28, 29, 31, 32, 35, 36, 43, 49], 4 in Europe [33, 39, 44, 46], and 10 in Asia [30, 34, $37,38,40-42,45,47,48]$. The Newcastle-Ottawa scale (NOS) values ranged from four to eight stars; 12 of the 22 studies were of high quality [29-31, 35, 37, 40, 42, $44-46,48,49]$. The characteristics of the included studies are shown in Table 1.

\section{Meta-analysis}

\section{Smoking and risk of CCA}

A total of 22 case-control studies involving 7,216 CCA cases and 317,117 control cases were analyzed [28-49]. Significant heterogeneity existed among the studies $\left(P=0.001 ; \mathrm{I}^{2}=52.6 \%\right)$. The summary odds ratio (OR) of CCA was 1.31 [95\% confidence interval (CI), 1.15 to 1.51 ] in the random-effects model for smokers versus nonsmokers (Figure 2). Among these studies, only one study investigated the association between current smoking and risk of CCA, and the results indicated an increased risk of CCA among current smokers (OR, 1.38; 95\% CI, 1.01 to 1.87 ) [39]. Upon evaluating the 21 studies with data for ever smoker only, the pooled data showed that the association between smoking and risk of CCA was similar (OR, $1.31 ; 95 \% \mathrm{CI}, 1.13$ to 1.51$)$. The association between current smokers and ever smokers with the risk of CCA was not different.

Subgroup meta-analyses by study location, study quality, and adjustment for confounders were then performed (Table 2). A significant positive association existed between smoking and risk of CCA in both highquality studies (OR, 1.23;95\% CI, 1.13 to 1.34 ) and low-quality studies (OR, $1.35 ; 95 \% \mathrm{CI}, 1.00$ to 1.83 ). A positive association between smoking and risk of CCA was observed in studies performed in Western countries (OR, 1.44; 95\% CI, 1.20 to 1.73 ), and a positive, but not significant association was found in studies performed in Asian countries (OR, 1.17; 95\% CI, 0.97 to 1.42 ). When we limited the meta-analysis to studies that adjusted for potential confounders, the pooled data also showed an increased risk of developing CCA in smokers in the studies that adjusted for diabetes mellitus (OR, 1.30; 95\% CI, 1.16 to 1.45 ), cholelithiasis (OR, $1.35 ; 95 \% \mathrm{CI}, 1.05$ to 1.72 ), and liver cirrhosis (OR, $1.29 ; 95 \% \mathrm{CI}, 1.15$ to 1.44$)$.

\section{Smoking and risk of intrahepatic CCA}

Twelve studies involving 3,759 patients with intrahepatic CCA and 308,278 healthy controls investigated the association between smoking and risk of intrahepatic CCA [30, 34-38, 40, 42-44, 46, 49]. A significant heterogeneity existed among the studies $\left(P=0.000 ; \mathrm{I}^{2}=66.2 \%\right)$. The pooled data using the random effects model showed an increased OR of developing intrahepatic CCA in smokers (OR, $1.31 ; 95 \%$ CI, 1.06 to 1.63) (Figure 3).

In the subgroup meta-analyses, a positive significant association was found between smoking and risk of intrahepatic CCA in western studies (OR, 1.54; 95\% CI, 1.08 to 2.19 ) and high-quality studies (OR, 1.17; 95\% CI, 1.05 to 1.31$)$. The association between smoking and risk of intrahepatic CCA was positive, but not significant in studies performed in Asian countries (OR, 1.11; 95\% CI, 0.96 to 1.30 ) and low quality studies (OR, 1.44; 95\% CI, 0.90 to 2.32). When the meta-analysis was limited to studies that adjusted for potential confounders, the pooled data showed an increased risk of developing CCA in smokers in the studies that adjusted for diabetes mellitus (OR, 1.22; 95\% CI, 1.04 to 1.43), cholelithiasis (OR, 1.45; 95\% CI, 1.01 to 2.08 ) , and liver cirrhosis (OR, 1.22; 95\% CI, 1.04 to 1.43 ).

\section{Smoking and risk of extrahepatic CCA}

Twelve studies involving 3029 patients with extrahepatic CCA and 110,608 healthy controls explored the association between smoking and risk of extrahepatic CCA [29, 31, 35, 36, 40, 41, 44-49]. A significant heterogeneity existed among the studies $\left(P=0.034 ; \mathrm{I}^{2}=\right.$ $45.1 \%)$. The pooled data using the random-effects model showed that smoking was associated with improved risk 
Table 1: Characteristics of included case-control studies

\begin{tabular}{|c|c|c|c|c|c|c|c|c|c|}
\hline First author & Country & $\begin{array}{c}\text { Type of } \\
\text { carcinoma }\end{array}$ & Cases $(N)$ & Contrls $(N)$ & $\begin{array}{l}\text { Study } \\
\text { period }\end{array}$ & Study population & $\begin{array}{c}\text { Definition of smoking (ever, } \\
\text { current) }\end{array}$ & $\begin{array}{c}\text { Adjustment } \\
\text { factors" }\end{array}$ & $\begin{array}{l}\text { NOS } \\
\text { value }\end{array}$ \\
\hline Ghadirian et al. 1993 [28] & Canada & $\mathrm{CCA}$ & 24 & 239 & $1984-1988$ & Men and women & Ever: NR & $1-6$ & 6 \\
\hline Chow et al. 1994 [29] & USA & $\mathrm{eCCA}$ & 62 & 248 & 1985-1989 & Men and women & Ever: NR & 1,2 & 8 \\
\hline Shin et al. 1996 [30] & Korea & iCCA & 41 & 406 & $1990-1993$ & Men and women & $\begin{array}{l}\text { Ever: Heavy smoking: }>1 \text { pack } \\
\text { per day for }>10 \text { years }\end{array}$ & $1,2,7$ & 8 \\
\hline Khan et al. 1999 [31] & USA & $\mathrm{eCCA}$ & 31 & 138 & 1980-1994 & Men and women & Ever: NR & $1,2,7-9$ & 8 \\
\hline Chalasani et al. 2000 [32] & USA & $\mathrm{CCA}$ & 26 & 87 & $1991-1998$ & $\begin{array}{l}\text { Men and women with primary } \\
\text { sclerosing cholangitis }\end{array}$ & Ever: NR & 10,11 & 4 \\
\hline Kuper et al. 2001 [33] & Greece & $\mathrm{CCA}$ & 6 & 360 & 1995-1998 & Men and women & Ever: NR & 1,2 & 5 \\
\hline Yamamoto et al. 2004 [34] & Japan & iCCA & 50 & 205 & 1991-2002 & Men and women & Ever: NR & 2,12 & 6 \\
\hline Shaib et al. 2007 [35] & USA & $\mathrm{iCCA}+\mathrm{eCCA}$ & 246 & 236 & 1992-2002 & Men and women & Ever: NR & $1,2,8$ & 8 \\
\hline Welzel et al. 2007 [36] & USA & $\mathrm{iCCA}+\mathrm{eCCA}$ & 1,084 & 102,782 & 1993-1999 & Men and women ( $\geq 65 \mathrm{y})$ & Ever: NR & $1,2,8,11,13$ & 6 \\
\hline Lee et al. 2008 [37] & Korea & $\mathrm{iCCA}$ & 622 & 2,488 & $2000-2004$ & Men and women & $\begin{array}{l}\text { Ever: Subjects were considered } \\
\text { smokers if they had smoked for } \\
\text { any time before admission }\end{array}$ & $1,2,14$ & 8 \\
\hline Zhou et al. 2009 [38] & China & iCCA & 317 & 634 & 2003-2006 & Men and women & Ever: NR & $\begin{array}{l}1,2,4,8,9,11, \\
15-21\end{array}$ & 6 \\
\hline Grainge et al. 2009 [39] & UK & $\mathrm{CCA}$ & 372 & 5,760 & $1987-2002$ & Men and women & Current: NR & $1,2,22$ & 5 \\
\hline Tao et al. 2010 [40] & China & $\mathrm{iCCA}+\mathrm{eCCA}$ & 190 & 380 & 1998-2008 & Men and women & Ever: NR & 1,2 & 8 \\
\hline Cai et al. 2011 [41] & China & $\mathrm{hCCA}$ & 313 & 608 & $2000-2005$ & Men and women & Ever: NR & $1,2,23$ & 6 \\
\hline Liu et al. 2011 [42] & China & $\mathrm{iCCA}$ & 87 & 228 & $2000-2008$ & $\begin{array}{l}\text { Men and women with } \\
\text { hepatolithiasis }\end{array}$ & $\begin{array}{l}\text { Ever: A smoker was defined as } \\
\text { someone who had smoked } 20 \\
\text { cigarettes or more per day for } \\
\text { more than } 1 \text { year }\end{array}$ & $\begin{array}{l}1,2,9,11,14 \\
24,25\end{array}$ & 8 \\
\hline Welzel et al. 2011 [43] & USA & iCCA & 743 & 195,953 & $1993-2005$ & Men and women ( $\geq 65 \mathrm{y})$ & Ever: NR & $1,2,8,11,26$ & 6 \\
\hline Onal et al. 2012 [44] & Turkey & $\mathrm{iCCA}+\mathrm{eCCA}$ & 99 & 48 & 2006-2010 & Men and women & $\begin{array}{l}\text { Ever: Ever having smoked } \\
\text { cigarettes was defined as having } \\
\text { smoked cigarettes } \geq 6 \mathrm{~d} / \mathrm{wk} \text { for } \\
\geq 6 \mathrm{mo} \text {. }\end{array}$ & 1,2 & 7 \\
\hline Zhou et al. 2013 [45] & China & $\mathrm{eCCA}$ & 239 & 478 & 1999-2011 & Men and women & Ever: NR & $\begin{array}{l}1,2,9,16,20 \\
24,27\end{array}$ & 7 \\
\hline Brandi et al. 2013 [46] & Italy & $\mathrm{iCCA}+\mathrm{eCCA}$ & 100 & 361 & 2006-2010 & Men and women & Ever: NR & $1,2,11$ & 7 \\
\hline Hosono et al. 2014 [47] & Japan & $\mathrm{eCCA}$ & 88 & 547 & 2009-2013 & Men and women & Ever: NR & 1,2 & - \\
\hline Lee et al. 2015 [48] & Korea & $\mathrm{pCCA}$ & 81 & 162 & $2007-2013$ & Men and women & Ever: NR & $1,2,9,14,20$ & 7 \\
\hline Choi et al. 2016 [49] & USA & $\begin{array}{l}\text { iCCA + pCCA } \\
+ \text { dCCA }\end{array}$ & 2,395 & 4,769 & $2000-2014$ & Men and women & $\begin{array}{l}\text { Ever: Ever-smoker was defined } \\
\text { as any person having a history of } \\
\text { smoking }\end{array}$ & $\begin{array}{l}1,2,8,10,16 \\
20,28-35\end{array}$ & 8 \\
\hline
\end{tabular}

Abbreviations: CCA: cholangiocarcinoma; iCCA: intrahepatic cholangiocarcinoma; eCCA: extrahepatic cholangiocarcinoma; hCCA: hilar cholangiocarcinoma; pCCA: perihilar cholangiocarcinoma; dCCA: distal cholangiocarcinoma; NOS, Newcastle-Ottawa scale; NR: not reported (number of cigarettes and period of smoking).

"1, Age; 2, sex; 3, other smoking habits; 4, alcohol consumption; 5, schooling; 6, respondent status; 7, socioeconomic status; 8, ethnicity; 9, cholelithiasis; 10, primary sclerosing cholangitis; 11, geographic location; 12, operation date; 13, state buy-in status; 14 , date of admission or diagnosis; 15 , HBV; 16, liver cirrhosis; 17 , hepatic cyst; 18 , hepatic hemangioma; 19 , fatty liver; 20, diabetes mellitus; 21 , hepatic schistosomiasis; 22 , general practice group; 23 , the year of search; 24, family history of cancer,; 25, appendectomy during childhood; 26, Medicare/Medicaid Dual Enrollment; 27, history of cholecystectomy; 28, obesity; 29, hypertension; 30, cerebrovascular accident; 31, coronary artery disease; 32, peripheral vascular disease; 33, atrial fibrillation; 34, nonalcoholic fatty liver disease/nonalcoholic steatohepatitis; 35 , inflammatory bowel disease.

of extrahepatic CCA (OR, 1.32; 95\% CI, 1.10 to 1.59$)$ (Figure 4).

In the subgroup meta-analyses, a positive significant association was found between smoking and risk of extrahepatic CCA in studies performed in western countries (OR, 1.35; 95\% CI, 1.17 to 1.55$)$ and highquality studies (OR, $1.29 ; 95 \% \mathrm{CI}, 1.13$ to 1.47 ). The association between smoking and risk of extrahepatic CCA was positive, but not significant in studies performed in Asian countries (OR, 1.29; 95\% CI, 0.88 to 1.90$)$ and low-quality studies (OR, $1.18 ; 95 \% \mathrm{CI}, 0.63$ to 2.22 ). When the meta-analysis was limited to studies that adjusted for potential confounders, the pooled data showed a positive significant association between smoking and risk of extrahepatic CCA in the studies that adjusted for diabetes mellitus (OR, 1.36; 95\% CI, 1.16 to 1.58 ) and liver cirrhosis (OR, $1.35 ; 95 \% \mathrm{CI}, 1.15$ to 1.58 ), and a positive, but non-significant association was found in the studies that adjusted for cholelithiasis (OR, 1.26; 95\% CI, 0.90 to 1.77$)$.

\section{Sensitivity analysis and publication bias}

In sensitivity analysis, each study was excluded and its influence was evaluated by calculating the pooled OR for the rest of the studies. The analysis confirmed the stability of the result because none of the individual studies markedly affected the pooled effect. 
Table 2: Subgroup analysis

\begin{tabular}{|c|c|c|c|c|}
\hline \multirow{2}{*}{ Subgroups } & \multirow{2}{*}{ No. of studies } & \multirow{2}{*}{ OR $(95 \% \mathrm{CI})$} & \multicolumn{2}{|c|}{ Heterogeneity } \\
\hline & & & $I^{2}(\%)$ & $P$ value \\
\hline Risk of CCA & 22 & $1.31(1.15$ to 1.51$)$ & $52.6 \%$ & 0.001 \\
\hline \multicolumn{5}{|l|}{ Study location } \\
\hline Western & 12 & $1.44(1.20$ to 1.73$)$ & 49.1 & 0.012 \\
\hline Asian & 10 & $1.17(0.97$ to 1.42$)$ & 43.6 & 0.053 \\
\hline \multicolumn{5}{|l|}{ Study quality } \\
\hline High & 12 & $1.23(1.13$ to 1.34$)$ & 0.6 & 0.447 \\
\hline Low & 9 & 1.35 (1.00 to 1.83$)$ & 70 & 0.000 \\
\hline \multicolumn{5}{|l|}{ Adjustment for confounders } \\
\hline Adjustment for diabetes & 4 & $1.30(1.16$ to 1.45$)$ & 0.0 & 0.975 \\
\hline Adjustment for cholelithiasis & 5 & 1.35 (1.05 to 1.72$)$ & 0.0 & 0.526 \\
\hline Adjustment for liver cirrhosis & 3 & $1.29(1.15$ to 1.44$)$ & 0.0 & 0.999 \\
\hline Risk of intrahepatic CCA & 12 & $1.31(1.06$ to 1.63$)$ & 66.2 & 0.000 \\
\hline \multicolumn{5}{|l|}{ Study location } \\
\hline Western & 6 & 1.54 (1.08 to 2.19$)$ & 77.0 & 0.001 \\
\hline Asian & 6 & $1.11(0.96$ to 1.30$)$ & 6.2 & 0.380 \\
\hline \multicolumn{5}{|l|}{ Study quality } \\
\hline High & 8 & $1.17(1.05$ to 1.31$)$ & 6.3 & 0.383 \\
\hline Low & 4 & $1.44(0.90$ to 2.32$)$ & 77.1 & 0.004 \\
\hline \multicolumn{5}{|l|}{ Adjustment for confounders } \\
\hline Adjustment for diabetes & 2 & $1.22(1.04$ to 1.43$)$ & 0.0 & 0.797 \\
\hline Adjustment for cholelithiasis & 2 & $1.45(1.01$ to 2.08$)$ & 2.4 & 0.311 \\
\hline Adjustment for liver cirrhosis & 2 & $1.22(1.04$ to 1.43$)$ & 0.0 & 0.797 \\
\hline Risk of extrahepatic $\mathrm{CCA}^{*}$ & 12 & $1.32(1.10$ to 1.59$)$ & 45.1 & 0.034 \\
\hline \multicolumn{5}{|l|}{ Study location } \\
\hline Western & 7 & $1.35(1.17$ to 1.55$)$ & 15.8 & 0.301 \\
\hline Asian & 5 & $1.29(0.88$ to 1.90$)$ & 69.1 & 0.012 \\
\hline \multicolumn{5}{|l|}{ Study quality } \\
\hline High & 9 & $1.29(1.13$ to 1.47$)$ & 11.3 & 0.336 \\
\hline Low & 2 & $1.18(0.63$ to 2.22$)$ & 74.3 & 0.049 \\
\hline \multicolumn{5}{|l|}{ Adjustment for confounders } \\
\hline Adjustment for diabetes & 3 & $1.36(1.16$ to 1.58$)$ & 11.8 & 0.334 \\
\hline Adjustment for cholelithiasis & 3 & $1.26(0.90$ to 1.77$)$ & 0.0 & 0.397 \\
\hline Adjustment for liver cirrhosis & 2 & $1.35(1.15$ to 1.58$)$ & 39.2 & 0.193 \\
\hline
\end{tabular}

Abbreviations: CCA, cholangiocarcinoma; OR, odds ratio.

*Extrahepatic CCA includes extrahepatic CCA, hilar CCA, perihilar CCA and distal CCA that presented in the studies.

No evidence of significant publication bias was noted from visual inspection of the funnel plots (Figures 5-7), Begg's test or Egger's test for risk of CCA (Begg's $P=0.626$, Egger's $P=0.954)$, risk of intrahepatic CCA (Begg's $P=0.463$, Egger's $P=0.887$ ), or extrahepatic CCA (Begg's $P=0.584$, Egger's $P=0.564$ ).

\section{DISCUSSION}

The association between smoking and risk of CCA has been debated for a long time. By permitting a synthesis of data and providing an objective evaluation of the evidence, meta-analysis may be the resolution of 
controversy and uncertainty [50]. Our meta-analysis of 22 non-randomized studies demonstrated that smoking was associated with a modest but significantly increased risk of CCA. This modestly increased risk of CCA was consistently shown, irrespective of different study regions and discrepant quality of studies. Based on these findings, we believe that smoking increases the risk of CCA, although the effect is relatively small. This effect is much smaller compared with the associated risk in malignancies of the respiratory system and even lower compared with that of upper gastrointestinal carcinoma such as esophageal or gastric cancer $[14,51]$.

The pooled estimate from Asian populations was lower than that from Western populations. A similar difference was also observed in lung and bladder cancers. Gandini et al. [14] performed a meta-analysis to estimate the association between tobacco smoking and cancer risk, and their pooled data showed that the association of smoking with lung cancer in Asian populations was markedly lower than that in Caucasian populations. Van Osch et al. [52] performed a meta-analysis to assess the association between smoking and bladder cancer risk, and found that all studies in Asian populations showed lower ORs than pooled estimates from the United States and Europe. Why Asian populations present lower susceptibility for smoking-related cancers is still unclear. One explanation may be that nicotine intake from smoking is lower in Asian populations compared with that

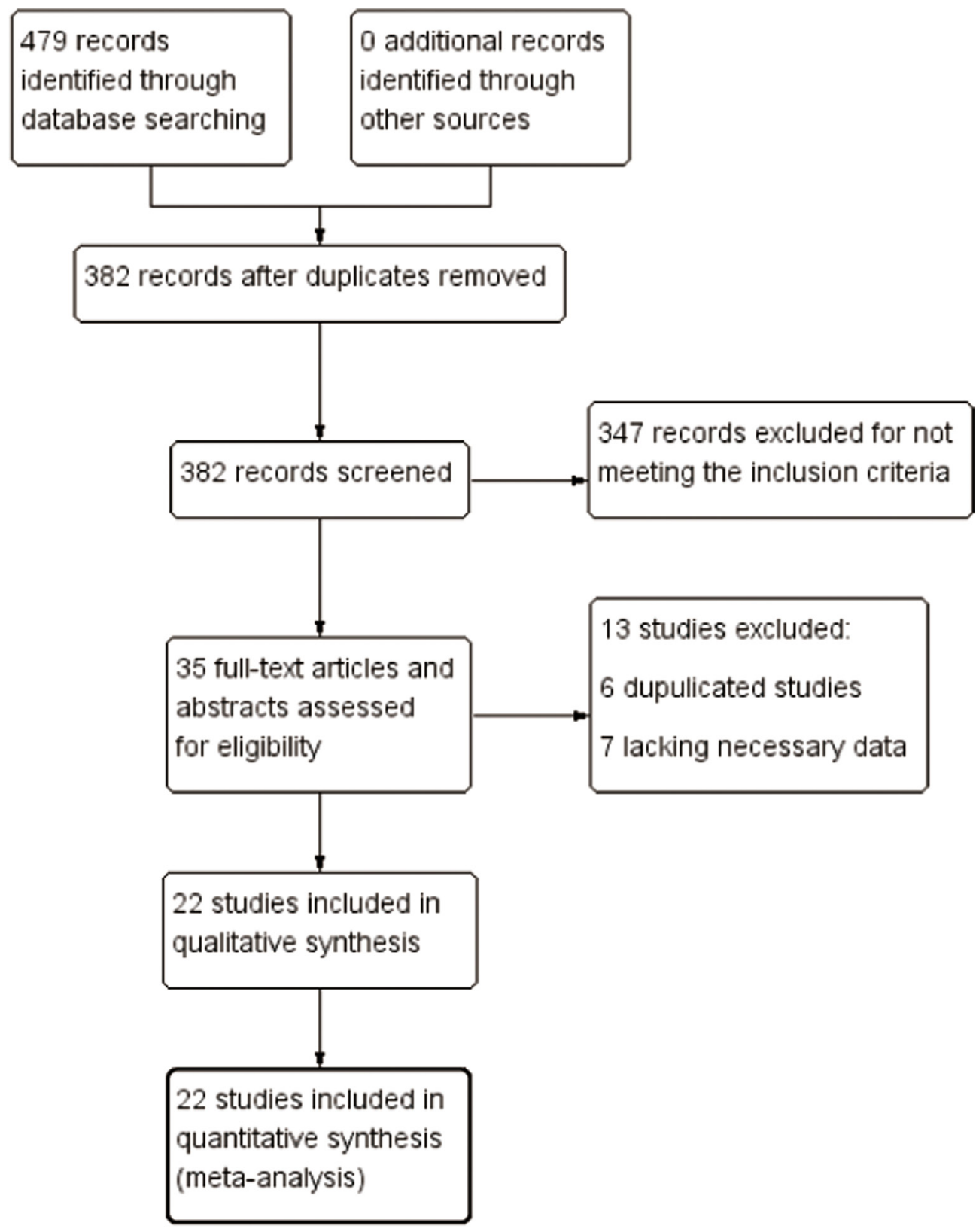

Figure 1: Study flow diagram. 


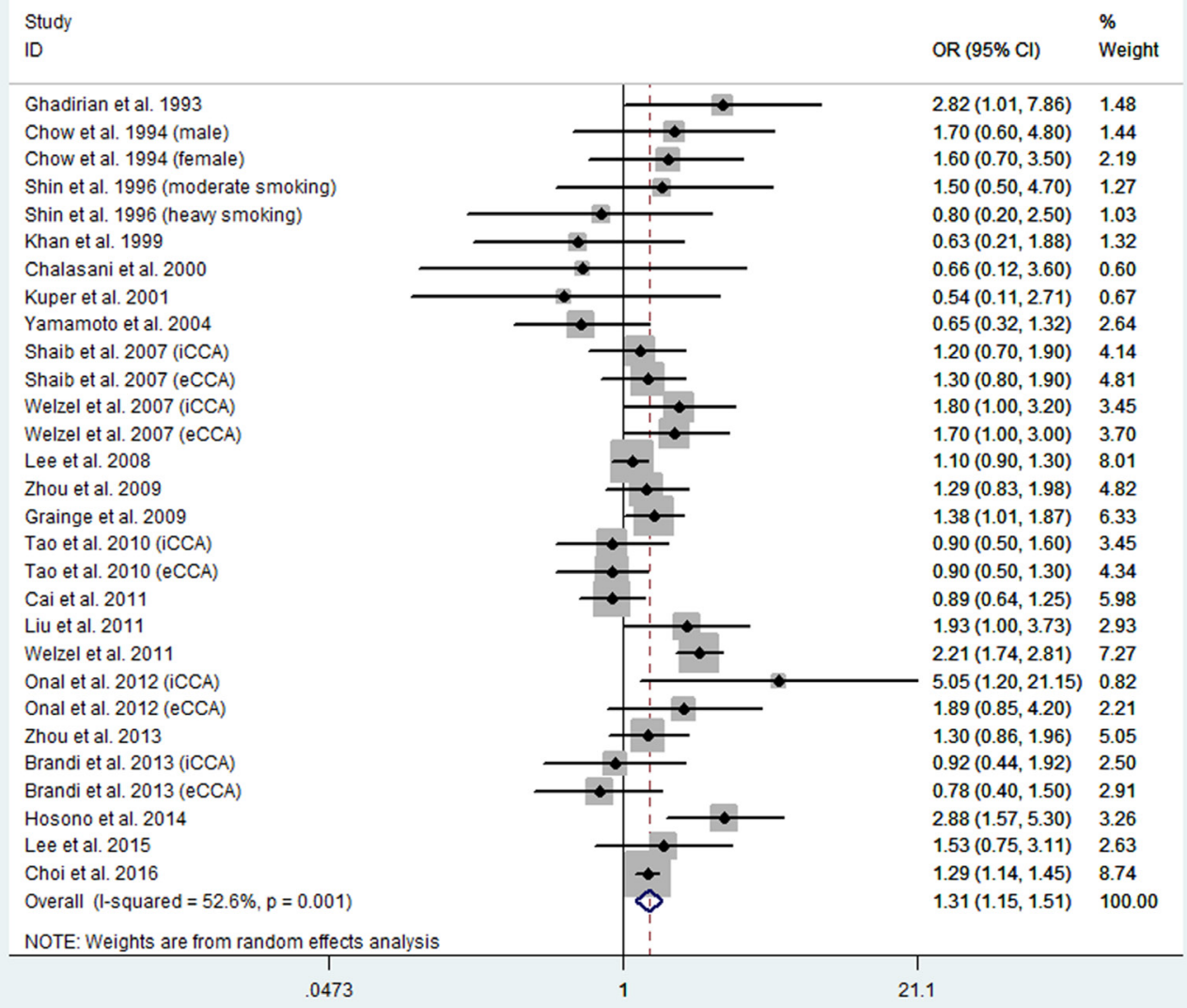

Figure 2: Forest plot of smoking and risk of CCA.

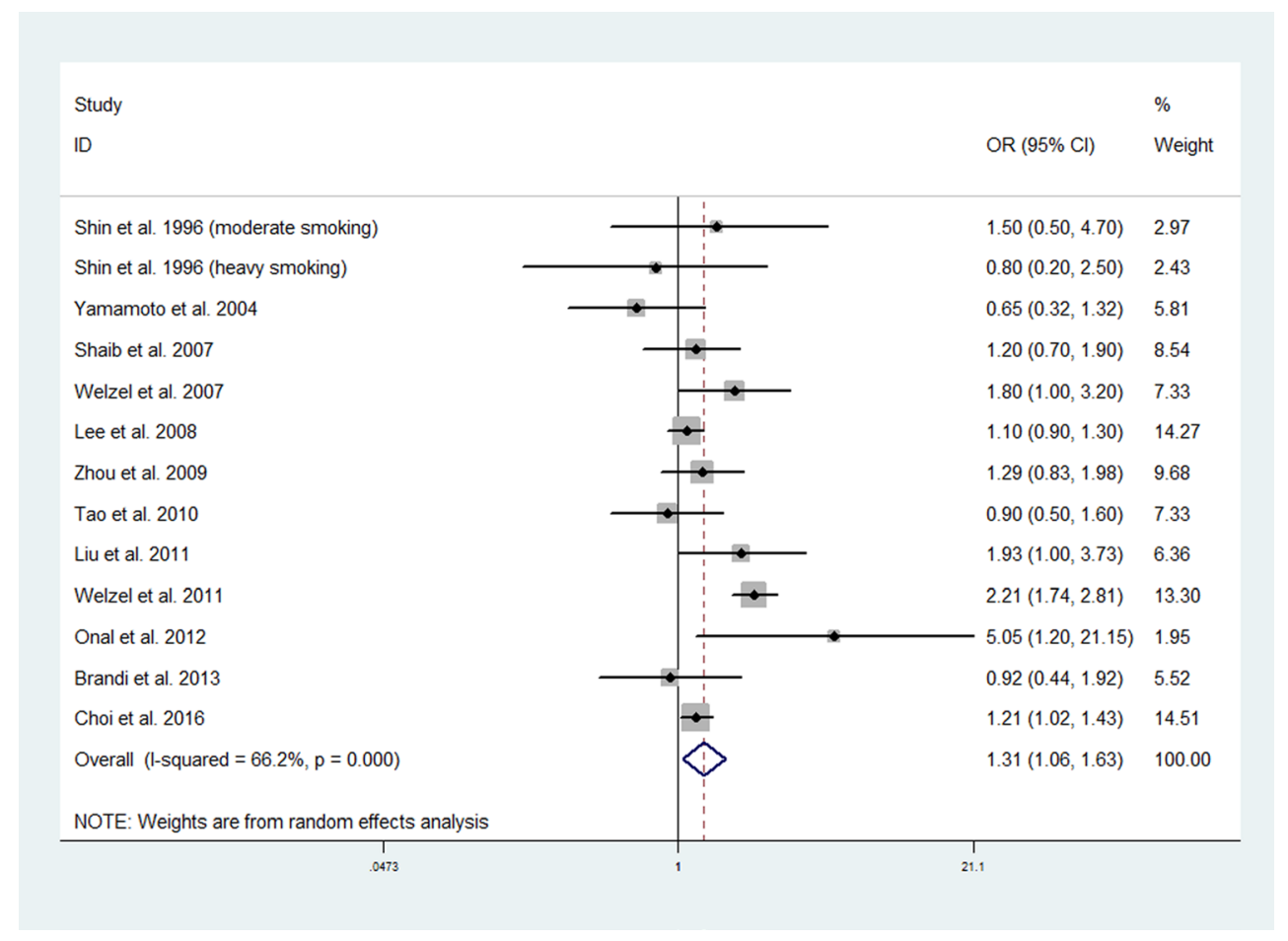

Figure 3: Forest plot of smoking and risk of intrahepatic CCA. 


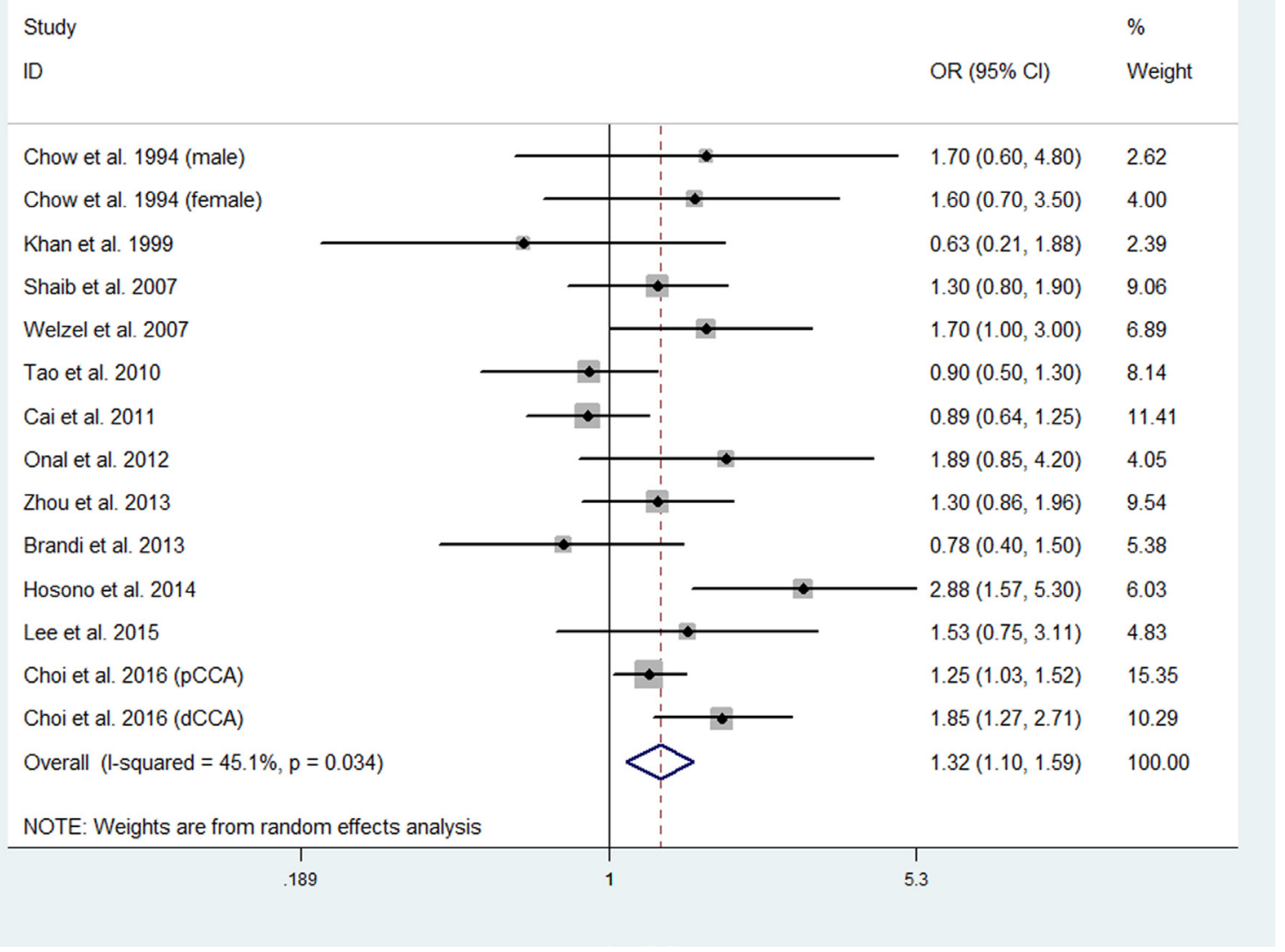

Figure 4: Forest plot of smoking and risk of extrahepatic CCA.

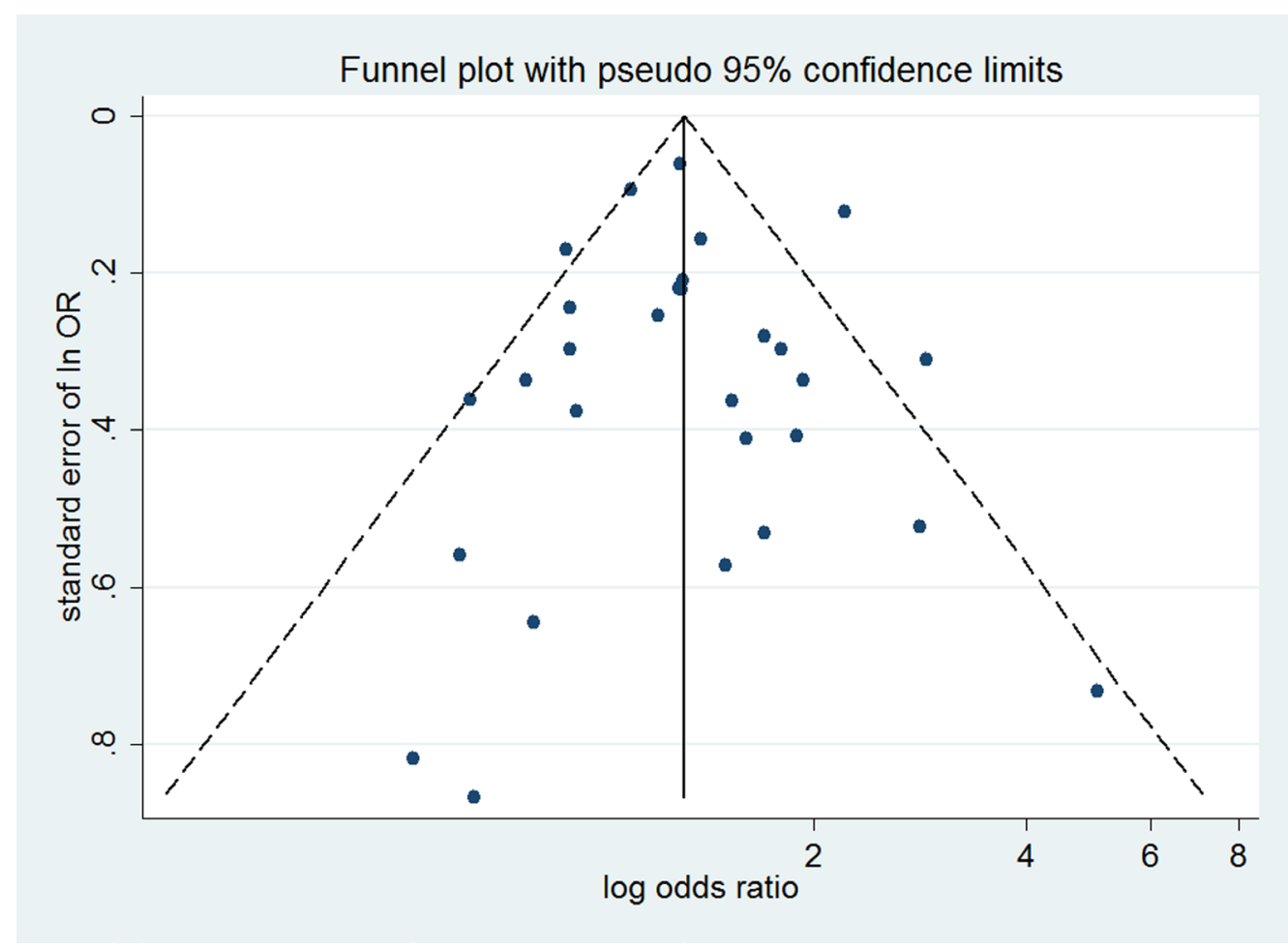

Figure 5: Funnel plot for assessing publication bias of smoking and risk of CCA. 


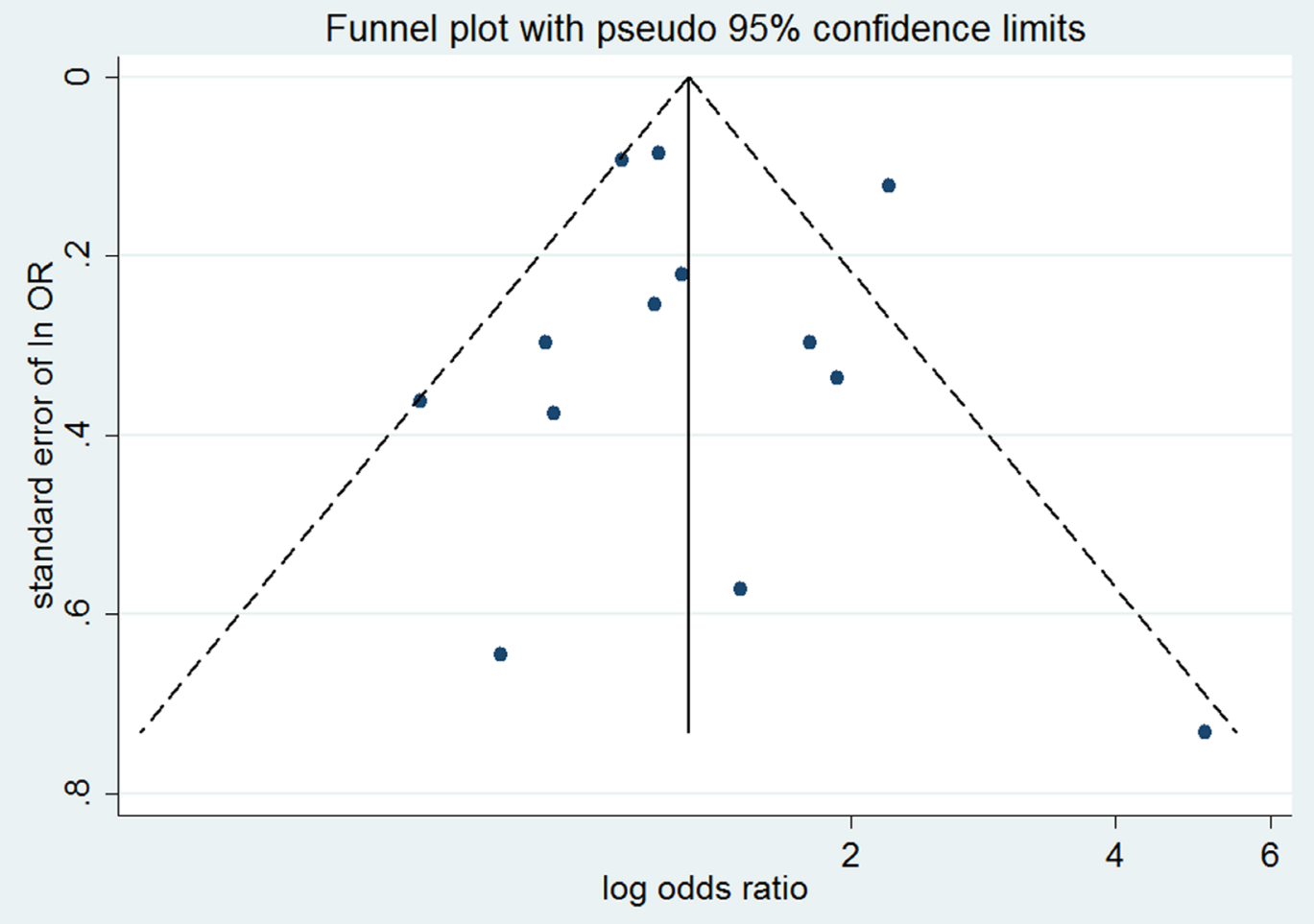

Figure 6: Funnel plot for assessing publication bias of smoking and risk of intrahepatic CCA.

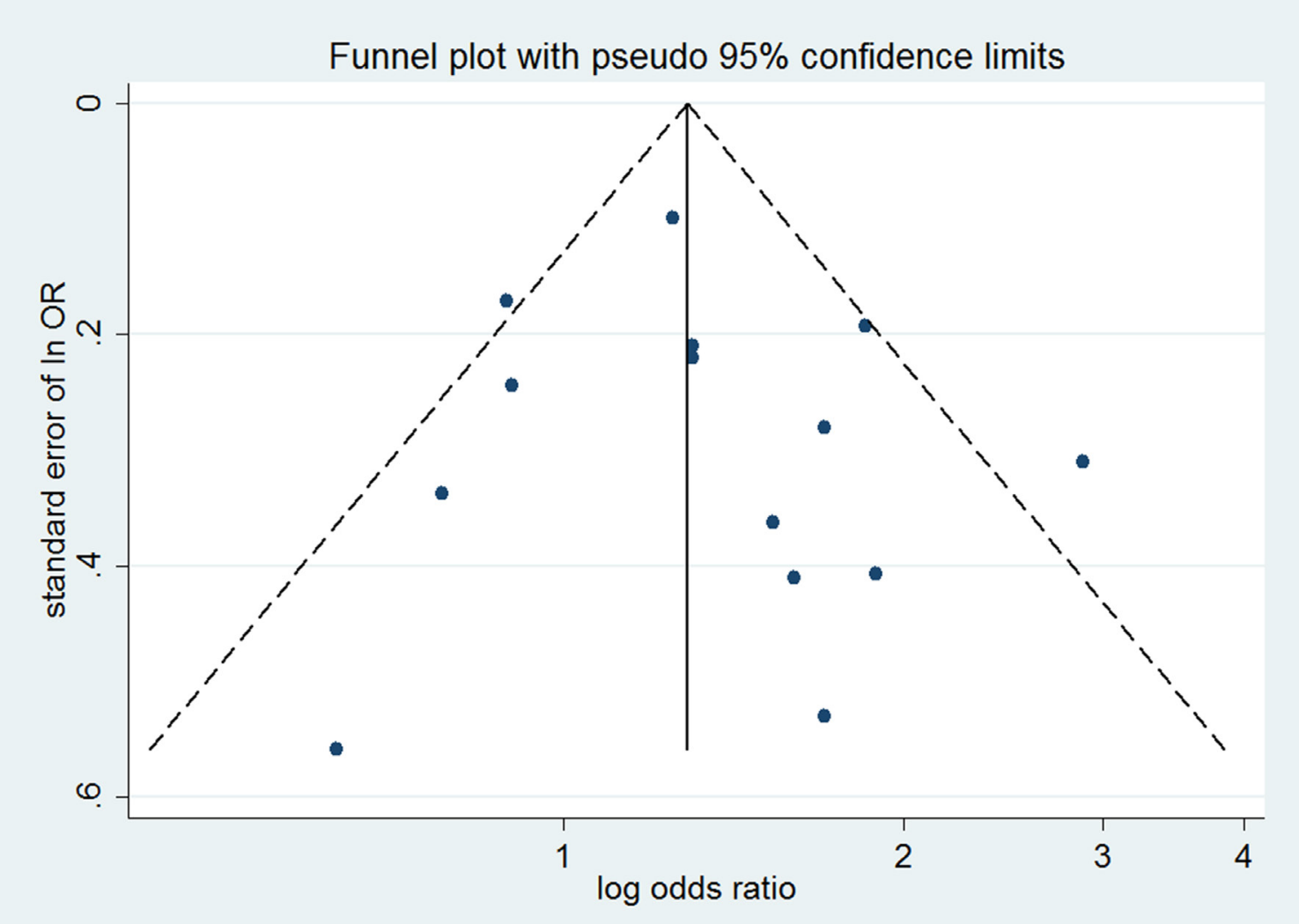

Figure 7: Funnel plot for assessing publication bias of smoking and risk of extrahepatic CCA. 
in Caucasian populations; thus Asian populations might be less susceptible to the harmful effects of cigarette smoking [53].

The results of our meta-analysis might be distorted by selection bias and confounding factors from nonrandomized studies [54]. In general, a meta-analysis of randomized controlled trials (RCTs) allows for a more objective assessment of evidence than that of nonrandomized studies. However, non-randomized studies should be retrieved for meta-analysis when RCTs are not available. To date, no RCTs have assessed the association between smoking and risk of CCA. Thus, this metaanalysis was conducted by pooling the findings from 22 non-randomized studies. Important risk factors of CCA, including diabetes mellitus, cholelithiasis, and liver cirrhosis, were carefully regarded as potential confounders in our analysis. The results showed that the association between smoking and risk of CCA remained unchanged after adjustment for these potential confounders. We could not evaluate any potential effect modification because the information on the effect modification between smoking and these CCA risk factors were limited.

Our results support that smoking is associated with increased risk of CCA, and such a relationship is further corroborated by biological plausibility. Several constituents in cigarette smoke have been shown to lead to the development of CCA in animal and human experiments. N-Nitrosodimethylamine, as mentioned in the introduction, can cause CCA in mice [13]. A strong relationship between vinyl chloride workers and CCA mortality has been reported [55]. Additionally, increased CCA risk due to arsenic in drinking water was also reported in the United States [56].

Our meta-analysis has some limitations. First, the adjustment factors were inconsistent across the studies. We attempted to employ the best adjusted estimate, which adjusted for as many potential confounders as possible. Second, all of the included studies were non-randomized studies owing to lack of relevant RCTs in the literature. Furthermore, one abstract without available full text was included in this meta-analysis, and the methodological quality was not assessed properly. Moreover, the information regarding the number of cigarettes smoked per day and duration of smoking was not provided in most studies, thus made evaluation of a dose-response trend difficult in this study.

In conclusion, the results of our meta-analysis support the hypothesis that there is a moderate association between cigarette smoking and risk of CCA. Further largescale and well-conducted studies that investigate potential effect modification with confounders and the doseresponse relationship between cigarette smoking and risk of CCA are needed. This conclusion delivers an important public health message to areas of both high CCA incidence and high smoking prevalence such as in China.

\section{MATERIALS AND METHODS}

This systematic review and meta-analysis was performed in accordance with the Preferred Reporting Items for Systematic Reviews and Meta-Analyses statement [57].

\section{Search strategy}

A systematic literature search of Embase, Pub Med, and Cochrane Central Register of Controlled Trials databases was performed to identify all relevant articles regarding the relationship between smoking and risk of CCA from inception to April 11, 2017. Both subject headings and free text words were used in the search. The following search terms were used: "smoking OR tobacco OR cigarette" AND "cholangiocarcinoma OR bile duct cancer". The following trial registers were also searched to find potentially relevant ongoing trials: International Standard Randomised Controlled Trial Number registry, World Health Organization International Clinical Trials Registry Platform, and ClinicalTrials.gov. Additionally, we screened the reference lists from all retrieved articles for relevant studies. No language restriction was imposed in our search strategy.

\section{Eligibility criteria}

Studies were included in this meta-analysis if they met the following criteria: (1) randomized controlled trials or non-randomized studies; (2) full-text articles and abstracts that included smoking as an exposure of interest; (3) the outcome of interest was CCA, intrahepatic CCA, extrahepatic CCA, perihilar CCA, or distal CCA; and (4) ORs or relative risk (RRs) with $95 \%$ CIs were reported or can be calculated. Studies were excluded if they were either of the following: (1) reviews, letters, editorials and case reports; (2) without data specific for CCA; (3) without appropriate data that could be extracted or calculated. In the case of multiple publications from the same population, only the most comprehensive one was included.

\section{Data extraction and quality assessment}

The following data were collected from each study: publication data (i.e., the first author's name, publication year, and study location), study design, study period, sample size, smoking status, OR (or RR) estimates with corresponding 95\% CIs, and adjusting factors. When multiple estimates of effect (OR) were presented, the most adjusted one was extracted; when an adjusted estimate was not available, crude estimate was extracted. We attempted to contact the authors of relevant studies for important unreported data by e-mail communication. Data 
extraction was conducted independently by two reviewers, with disagreements resolved by discussion with a third reviewer.

Because all included studies were non-randomized studies, their methodological quality was assessed independently by three reviewers using the NOS [58]. The NOS evaluates the study quality based on three aspects: namely selection, comparability, and exposure (casecontrol studies) or outcome (cohort studies), using a star rating system ranging from zero to nine stars. Studies with seven or more stars were considered to be of high quality.

\section{Statistical analysis}

Because the prevalence of cholangiocarcinoma is low, the RR mathematically approximates the OR [59]. The ORs with corresponding 95\% CIs from individual eligible studies were combined to obtain a pooled OR with 95\% CI. Statistical heterogeneity between studies was measured by using the Chi-square $\left(\chi^{2}\right.$, or $\left.\mathrm{Chi}^{2}\right)$ test and quantified via $\mathrm{I}^{2}$ statistic; $P$ value $<0.10$ or $\mathrm{I}^{2}>50 \%$ was considered statistically significant. When significant heterogeneity was observed, a random-effects model was used to calculate the pooled effect; otherwise, a fixedeffects model was applied. Once significant heterogeneity was found, we attempted to explore the causes of heterogeneity through a subgroup analysis by study location, study quality, and adjustment for confounders. To assess the stability of the results, we performed a sensitivity analysis by removing each study in the analysis at a time. Publication bias was estimated through both visual inspection of funnel plots and statistical evaluation with the Begg's funnel plot and Egger's tests [60, 61]. A two-sided $P$ value less than 0.05 was considered statistically significant. All analyses were conducted using Stata version 12.0 software (Stata Corporation, College Station, TX).

\section{CONFLICTS OF INTEREST}

The authors declare no conflicts of interest.

\section{REFERENCES}

1. Oliveira IS, Kilcoyne A, Everett JM, Mino-Kenudson M, Harisinghani MG, Ganesan K. Cholangiocarcinoma: classification, diagnosis, staging, imaging features, and management. Abdom Radiol (NY). 2017.

2. Doherty B, Nambudiri VE, Palmer WC. Update on the Diagnosis and Treatment of Cholangiocarcinoma. Curr Gastroenterol Rep. 2017; 19:2.

3. Rizvi S, Gores GJ. Emerging Molecular Therapeutic Targets for Cholangiocarcinoma. J Hepatol. 2017.

4. Plentz RR, Malek NP. Clinical presentation, risk factors and staging systems of cholangiocarcinoma. Best Pract Res Clin Gastroenterol. 2015; 29:245-252.
5. Li M, Li J, Li P, Li H, Su T, Zhu R, Gong J. Hepatitis B virus infection increases the risk of cholangiocarcinoma: a meta-analysis and systematic review. J Gastroenterol Hepatol. 2012; 27:1561-1568.

6. Ehlken H, Schramm C. Primary sclerosing cholangitis and cholangiocarcinoma: pathogenesis and modes of diagnostics. Dig Dis. 2013; 31:118-125.

7. Guglielmi A, Ruzzenente A, Valdegamberi A, Bagante F, Conci S, Pinna AD, Ercolani G, Giuliante F, Capussotti L, Aldrighetti L, Iacono C. Hepatolithiasis-associated cholangiocarcinoma: results from a multi-institutional national database on a case series of 23 patients. Eur J Surg Oncol. 2014; 40:567-575.

8. Matsumoto K, Onoyama T, Kawata S, Takeda Y, Harada K, Ikebuchi Y, Ueki M, Miura N, Yashima K, Koda M, Sakamoto T, Endo M, Horie Y, Murawaki Y. Hepatitis B and $\mathrm{C}$ virus infection is a risk factor for the development of cholangiocarcinoma. Intern Med. 2014; 53:651-654.

9. Shaib YH, El-Serag HB, Davila JA, Morgan R, McGlynn KA. Risk factors of intrahepatic cholangiocarcinoma in the United States: a case-control study. Gastroenterology. 2005; 128:620-626.

10. Watanapa $\mathrm{P}$, Watanapa WB. Liver fluke-associated cholangiocarcinoma. Br J Surg. 2002; 89:962-970.

11. Kato I, Kido C. Increased risk of death in thorotrast-exposed patients during the late follow-up period. Jpn J Cancer Res. 1987; 78:1187-1192.

12. IARC monographs on the evaluation of the carcinogenic risk of chemicals to humans: some N-nitroso compounds. IARC Monogr Eval Carcinog Risk Chem Man. 1978; 17:1-349.

13. Flavell DJ, Lucas SB. Promotion of N-nitrosodimethylamineinitiated bile duct carcinogenesis in the hamster by the human liver fluke, Opisthorchis viverrini. Carcinogenesis. 1983; 4:927-930.

14. Gandini S, Botteri E, Iodice S, Boniol M, Lowenfels AB, Maisonneuve P, Boyle P. Tobacco smoking and cancer: a meta-analysis. Int J Cancer. 2008; 122:155-164.

15. Shaib YH, El-Serag HB, Davila JA, Morgan R, McGlynn KA. Risk factors of intrahepatic cholangiocarcinoma in the United States: a case-control study. Gastroenterology. 2005; 128:620-626.

16. Zhou YM, Yin ZF, Yang JM, Li B, Shao WY, Xu F, Wang YL, Li DQ. Risk factors for intrahepatic cholangiocarcinoma: a case-control study in China. World J Gastroenterol. 2008; 14:632-635.

17. Tao LY, He XD, Cai L, Liu W, Ji WJ, Zhao L, Zhang SM. Case-control study of risk factors in cholangiocarcinoma. Zhonghua Zhong Liu Za Zhi. 2009; 31:759-763.

18. Chaiteerakij R, Yang JD, Harmsen WS, Slettedahl SW, Mettler TA, Fredericksen ZS, Kim WR, Gores GJ, Roberts RO, Olson JE, Therneau TM, Roberts LR. Risk factors for intrahepatic cholangiocarcinoma: association between metformin use and reduced cancer risk. Hepatology. 2013; 57:648-655. 
19. Choi J, Ghoz HM, Peeraphatdit T, Baichoo E, Addissie BD, Harmsen WS, Therneau TM, Olson JE, Chaiteerakij $\mathrm{R}$, Roberts LR. Aspirin use is associated with reduced risk of cholangiocarcinoma. Hepatology. 2015; 64:785-96.

20. Chaiteerakij R, Yang JD, Harmsen WS, Slettedahl SW, Mettler TA, Fredericksen ZS, Kim WR, Gores GJ, Roberts RO, Olson JE, Therneau TM, Roberts LR. Risk factors for intrahepatic cholangiocarcinoma (ICC): Associations between metformin or statin use and reduced cancer risk. Gastroenterology. 2012; 142:S920.

21. Yen S, Hsieh CC, MacMahon B. Extrahepatic bile duct cancer and smoking, beverage consumption, past medical history, and oral-contraceptive use. Cancer. 1987; 59:2112-2116.

22. Moerman CJ, Bueno de Mesquita HB, Runia S. Smoking, alcohol consumption and the risk of cancer of the biliary tract; a population-based case-control study in The Netherlands. Eur J Cancer Prev. 1994; 3:427-436.

23. Chow WH, McLaughlin JK, Hrubec Z, Fraumeni JF Jr. Smoking and biliary tract cancers in a cohort of US veterans. Br J Cancer. 1995; 72:1556-1558.

24. Bergquist A, Glaumann H, Persson B, Broomé U. Risk factors and clinical presentation of hepatobiliary carcinoma in patients with primary sclerosing cholangitis: a casecontrol study. Hepatology. 1998; 27:311-316.

25. Jee SH, Samet JM, Ohrr H, Kim JH, Kim IS. Smoking and cancer risk in Korean men and women. Cancer Causes Control. 2004; 15:341-348.

26. Tischendorf JJ, Meier PN, Strassburg CP, Klempnauer J, Hecker H, Manns MP, Krüger M. Characterization and clinical course of hepatobiliary carcinoma in patients with primary sclerosing cholangitis. Scand J Gastroenterol. 2006; 41:1227-1234.

27. Otani S, Kurozawa Y, Hosoda $\mathrm{T}, \mathrm{Mu} \mathrm{H}$, Onishi K, Yokoyama Y, Watanabe J, Sakamoto T, Endo K, Ikeguchi M. Relationship between daily habits and risk of death in patients with biliary tract cancer: a large-scale cohort study in Japan. Cancer Research. 2014; 74.

28. Ghadirian P, Simard A, Baillargeon J. A populationbased case-control study of cancer of the bile ducts and gallbladder in Quebec, Canada. Rev Epidemiol Sante Publique. 1993; 41:107-112.

29. Chow WH, McLaughlin JK, Menck HR, Mack TM. Risk factors for extrahepatic bile duct cancers: Los Angeles County, California (USA). Cancer Causes Control. 1994; 5:267-272.

30. Shin HR, Lee CU, Park HJ, Seol SY, Chung JM, Choi HC, Ahn YO, Shigemastu T. Hepatitis B and C virus, Clonorchis sinensis for the risk of liver cancer: a case-control study in Pusan, Korea. Int J Epidemiol. 1996; 25:933-940.

31. Khan ZR, Neugut AI, Ahsan H, Chabot JA. Risk factors for biliary tract cancers. Am J Gastroenterol. 1999; 94:149-152.

32. Chalasani N, Baluyut A, Ismail A, Zaman A, Sood G, Ghalib R, McCashland TM, Reddy KR, Zervos X, Anbari MA, Hoen H. Cholangiocarcinoma in patients with primary sclerosing cholangitis: a multicenter case-control study. Hepatology. 2000; 31:7-11.

33. Kuper H, Lagiou P, Mucci LA, Tamimi R, Benetou V, Trichopoulos D. Risk factors for cholangiocarcinoma in a low risk Caucasian population. Soz Praventivmed. 2001; 46:182-185.

34. Yamamoto S, Kubo S, Hai S, Uenishi T, Yamamoto T, Shuto T, Takemura S, Tanaka H, Yamazaki O, Hirohashi K, Tanaka T. Hepatitis $\mathrm{C}$ virus infection as a likely etiology of intrahepatic cholangiocarcinoma. Cancer Sci. 2004; 95:592-595.

35. Shaib YH, El-Serag HB, Nooka AK, Thomas M, Brown TD, Patt YZ, Hassan MM. Risk factors for intrahepatic and extrahepatic cholangiocarcinoma: a hospital-based casecontrol study. Am J Gastroenterol. 2007; 102:1016-1021.

36. Welzel TM, Graubard BI, El-Serag HB, Shaib YH, Hsing AW, Davila JA, McGlynn KA. Risk factors for intrahepatic and extrahepatic cholangiocarcinoma in the United States: a population-based case-control study. Clin Gastroenterol Hepatol. 2007; 5:1221-1228.

37. Lee TY, Lee SS, Jung SW, Jeon SH, Yun SC, Oh HC, Kwon S, Lee SK, Seo DW, Kim MH, Suh DJ. Hepatitis $\mathrm{B}$ virus infection and intrahepatic cholangiocarcinoma in Korea: a case-control study. Am J Gastroenterol. 2008; 103:1716-1720.

38. Zhou HB, Xu QR, Wang H, Zhou DX, Wang H, Wang Q, Zhou SS, Tu QQ, Sun ZQ, Ai L, Wu MC, Hu HP. Risk factors of intrahepatic cholangiocarcinoma: a case-control study. Zhonghua Gan Zang Bing Za Zhi. 2009; 17:935-939.

39. Grainge MJ, West J, Solaymani-Dodaran M, Aithal GP, Card TR. The antecedents of biliary cancer: a primary care case-control study in the United Kingdom. Br J Cancer. 2009; 100:178-180.

40. Tao LY, He XD, Qu Q, Cai L, Liu W, Zhou L, Zhang SM. Risk factors for intrahepatic and extrahepatic cholangiocarcinoma: a case-control study in China. Liver Int. 2010; 30:215-221.

41. Cai WK, Sima H, Chen BD, Yang GS. Risk factors for hilar cholangiocarcinoma: a case-control study in China. World J Gastroenterol. 2011; 17:249-253.

42. Liu ZY, Zhou YM, Shi LH, Yin ZF. Risk factors of intrahepatic cholangiocarcinoma in patients with hepatolithiasis: a case-control study. Hepatobiliary Pancreat Dis Int. 2011; 10:626-631.

43. Welzel TM, Graubard BI, Zeuzem S, El-Serag HB, Davila JA, McGlynn KA. Metabolic syndrome increases the risk of primary liver cancer in the United States: a study in the SEER-Medicare database. Hepatology. 2011; 54:463-471.

44. Onal IK, Kekilli M, Alioglu H, Sayilir A, Sasma N, Parlak E, Kurt M, Disibeyaz S, Beyazit Y. Hepatitis B and C Virus Infection and Cholangiocarcinoma: A Case-Control Study in Turkey. UHOD. 2012; 22:187-191.

45. Zhou Y, Zhou Q, Lin Q, Chen R, Gong Y, Liu Y, Yu M, Zeng B, Li K, Chen R, Li Z. Evaluation of risk factors 
for extrahepatic cholangiocarcinoma: ABO blood group, hepatitis B virus and their synergism. Int J Cancer. 2013; 133:1867-1875.

46. Brandi G, Di Girolamo S, Farioli A, de Rosa F, Curti S, Pinna AD, Ercolani G, Violante FS, Biasco G, Mattioli S. Asbestos: a hidden player behind the cholangiocarcinoma increase? Findings from a case-control analysis. Cancer Causes Control. 2013; 24:911-918.

47. Hosono K, Ishii K, Fujita Y, Sekino Y, Nakajima A, Kubota K. Risk factors for intrahepatic and extrahepatic cholangiocarcinoma: A case-control study in Japan. United European Gastroenterol J. 2014; 2:A466.

48. Lee BS, Cha BH, Park EC, Roh J. Risk factors for perihilar cholangiocarcinoma: a hospital-based case-control study. Liver Int. 2015; 35:1048-1053.

49. Choi J, Ghoz HM, Peeraphatdit T, Baichoo E, Addissie BD, Harmsen WS, Therneau TM, Olson JE, Chaiteerakij R, Roberts LR. Aspirin use and the risk of cholangiocarcinoma. Hepatology. 2016; 64:785-796.

50. Demierre MF, Higgins PD, Gruber SB, Hawk E, Lippman SM. Statins and cancer prevention. Nat Rev Cancer. 2005; 5:930-942.

51. Sasco AJ, Secretan MB, Straif K. Tobacco smoking and cancer: a brief review of recent epidemiological evidence. Lung Cancer. 2004; 45:S3-S9.

52. van Osch FH, Jochems SH, van Schooten FJ, Bryan RT, Zeegers MP. Quantified relations between exposure to tobacco smoking and bladder cancer risk: a meta-analysis of 89 observational studies. Int J Epidemiol. 2016; 45:857-870.

53. Benowitz NL, Pérez-Stable EJ, Herrera B, Jacob P 3rd. Slower metabolism and reduced intake of nicotine from cigarette smoking in Chinese-Americans. J Natl Cancer Inst. 2002; 94:108-115.

54. Egger M, Schneider M, Davey Smith G. Spurious precision? Meta-analysis of observational studies. BMJ. 1998; 316:140-144.

55. Monson RR, Peters JM, Johnson MN. Proportional mortality among vinyl-chloride workers. Lancet. 1974; 2:397-398.

56. Han YY, Weissfeld JL, Davis DL, Talbott EO. Arsenic levels in ground water and cancer incidence in Idaho: an ecologic study. Int Arch Occup Environ Health. 2009; 82:843-849.

57. Moher D, Liberati A, Tetzlaff J, Altman DG; PRISMA Group. Preferred reporting items for systematic reviews and meta-analyses: the PRISMA statement. Int J Surg. 2010; 8:336-341.

58. Wells GA, Shea B, O'Connell D, Peterson J, Welch V, Losos M, Tugwell P. The Newcastle-Ottawa Scale (NOS) for assessing the quality of nonrandomised studies in meta-analyses. http://www.ohri.ca/programs/clinical_ epidemiology/oxford.asp. [Accessed 15 April 2017].

59. Zhang J, Yu KF. What's the relative risk? A method of correcting the odds ratio in cohort studies of common outcomes. JAMA. 1998; 280:1690-1691.

60. Begg CB, Mazumdar M. Operating characteristics of a rank correlation test for publication bias. Biometrics. 1994; 50:1088-1101.

61. Egger M, Davey Smith G, Schneider M, Minder C. Bias in meta-analysis detected by a simple, graphical test. BMJ. 1997; 315:629-634. 